\title{
Osteomielite crônica pós-operatória nos ossos longos - O que sabemos e como conduzir esse problema*
}

\section{Postoperative Chronic Osteomyelitis in the Long Bones - Current Knowledge and Management of the Problem}

\author{
Lourenço Galizia Heitzmann ${ }^{1}$ (1) Raphael Battisti ${ }^{1}$ Ayres Fernando Rodrigues ${ }^{1}$ \\ Juliano Valente Lestingi ${ }^{1}$ Cinthya Cavazzana ${ }^{1}$ Roberto Dantas Queiroz ${ }^{1}$ \\ 1 Serviço de Ortopedia e Traumatologia, Hospital do Servidor Público
Estadual Francisco Morato de Oliveira, São Paulo, SP, Brasil \\ Rev Bras Ortop 2019;54:627-635. \\ Endereço para correspondência: Lourenço Galizia Heitzmann, MD, \\ Serviço de Ortopedia e Traumatologia, Hospital do Servidor Público \\ Estadual Francisco Morato de Oliveira, São Paulo, SP, Brasil \\ (e-mail: lourenco@heitzmann.com.br).
}

\section{Resumo \\ Palavras-chave \\ - osteomielite \\ - complicações pós- operatórias \\ - infecções bacterianas}

A osteomielite crônica pós-operatória é um problema de saúde importante devido à sua morbidade significativa e baixa taxa de mortalidade. Essa patologia se apresenta como um desafio do ponto de vista de compreensão da patogenia e também de escolha da estratégia de tratamento. $\mathrm{O}$ objetivo deste artigo foi revisar o tema proposto quanto à sua definição, patogenia, aspectos clínicos, diagnóstico e tratamento, e reunir todas essas informações em uma única publicação brasileira de caráter de atualização.

Foram feitas buscas nas bases de dados PubMed, Lilacs e Cochrane Library com palavraschave pertinentes ao tema, e foram escolhidos trabalhos atuais e de relevância.

Este trabalho permitiu reunir informações clássicas e inovações relacionadas à osteomielite crônica e seu tratamento, e oferecer material de atualização para auxiliar os profissionais envolvidos no tratamento dessa doença na tomada de decisão terapêutica.

Chronic postoperative osteomyelitis represents an important health problem due to its significant morbidity and low mortality rate. This pathology is challenging because of difficulties in understanding the pathogenesis and the decision-making involving the treatment. The present article had the goal of reviewing the definition, pathogenesis, clinical aspects, diagnosis, and treatment of chronic postoperative osteomyelitis, and of gathering this information in a single Brazilian update publication.

Keywords

- osteomyelitis The PubMed, LILACS, and the Cochrane Library medical databases were analyzed, using pertinent keywords. Current and relevant articles were selected.

The present article gathered the established information, as well as innovations related to chronic osteomyelitis and its treatment, offering updated data to assist the professionals involved in the management of chronic osteomyelitis.

Originalmente Publicado por Elsevier Editora Ltda.

recebido

12 de Julho de 2017

aceito

14 de Dezembro de 2017
DOI https://doi.org/

10.1016/j.rbo.2017.12.013. ISSN 0102-3616.
Copyright $\odot 2019$ by Sociedade Brasileira License terms de Ortopedia e Traumatologia. Published by Thieme Revinter Publicações Ltda, Rio de Janeiro, Brazil 


\section{Introdução}

A osteomielite, como termo médico, está presente na literatura especializada desde sua citação por Nelaton, em 1844, como um processo inflamatório de origem infecciosa no osso. Porém, a manifestação clínica de ferida secretiva após ferimento é citada na história desde placas entalhadas na Suméria. 0 tratamento baseava-se em manter a ferida aberta para a eliminação da secreção purulenta, com a aplicação local de unguentos e outras substâncias.

Com o advento da anestesia e a expansão dos procedimentos cirúrgicos, assim como a descoberta dos antibióticos, ocorreram mudanças significativas na maneira de conduzir o tratamento da osteomielite, tanto do ponto de vista clínico quanto cirúrgico. ${ }^{1}$

A osteomielite crônica é a entidade infecciosa em que o processo se encontra instalado e presente há mais de um mês. Pode ser ocasionada por um processo infeccioso agudo tratado incorretamente, infecção óssea por contiguidade a partir de infecção crônica de partes moles adjacentes, entre outras situações.

A osteomielite crônica pós-operatória representa um problema de saúde importante devido à sua morbidade significativa e baixa taxa de mortalidade. ${ }^{2,3}$ Essa infecção ocorre em aproximadamente 5 a $50 \%$ das fraturas abertas, em menos de $1 \%$ das fraturas fechadas com osteossíntese, e em $5 \%$ como causa da disseminação hematogênica aguda. ${ }^{3} \mathrm{O}$ principal problema associado à infecção óssea crônica é a capacidade dos microrganismos de permanecer no tecido ósseo necrótico e aumentar sua sobrevivência.

Em resumo, esse tema tem sido continuamente revisado e atualizado quanto à compreensão da patogenia, e às classificações e opções de tratamento com o advento de novas técnicas cirúrgicas e inovações medicamentosas.

O objetivo deste artigo é revisar o tema proposto quanto à sua definição, patogenia, aspectos clínicos, diagnóstico e tratamento, e reunir todas essas informações em uma única publicação brasileira.

\section{Material e Métodos}

Para a confecção deste artigo de atualização da literatura, fez-se a coleta de dados por meio da busca de artigos científicos nas bases de dados PubMed, BVS-Lilacs e Cochrane Library. Foram selecionadas três palavras-chave (MeSH terms) relevantes à proposta do tema: osteomyelitis, chronic e long bones.

Na Pubmed, os termos foram buscados de forma isolada, e nas combinações de dois dos três termos (osteomyelitis AND chronic; e osteomyelitis AND long bones). Os tipos de artigos filtrados para inclusão foram principalmente as revisões (overviews), e guias de prática clínica. Foram excluídos os trabalhos sobre osteomielite crônica de vértebras ou pelve relacionados à presença de prótese articular e infecção de origem hematogênica exclusivamente, e que envolviam apenas a população pediátrica.

Na BVS-Lilacs, os três termos foram aplicados à busca ao mesmo tempo, associados aos mesmos critérios de exclusão.
Na Cochrane Library, foi usado o termo chronic osteomyelitis para a busca de revisões sistemáticas.

\section{Resultados}

A partir da busca na base de dados Pubmed, foram encontrados 75 artigos para a primeira combinação de termos (osteomyelitis AND long bones), e 587 para a segunda combinação (osteomyelitis AND chronic), quando aplicados os critérios de inclusão e exclusão. Na base BVS-Lilacs, foram encontrados 142 artigos. As informações usadas para compor esta revisão partiram desse material encontrado, além das fontes bibliográficas contidas nesses trabalhos, mediante busca direta em um segundo momento. Na Cochrane Library, foram encontradas apenas duas revisões sistemáticas sobre osteomielite.

Foram selecionados artigos atuais e os considerados de maior relevância e qualidade para a composição deste trabalho de atualização.

\section{Discussão}

O conhecimento médico reunido por meio da busca na literatura sobre a osteomielite crônica nos ossos longos pode ser organizado de forma didática nos tópicos: definição (já explicado anteriormente), classificação, patogenia e aspectos relacionados ao desenvolvimento da doença, manifestações clínicas, diagnóstico clínico, propedêutica armada, e tratamento.

\section{Classificação da osteomielite}

A evolução da compreensão médica sobre a osteomielite resultou em diversos sistemas de classificação propostos ao longo do tempo.

Historicamente, existem as classificações etiológicas de Kelly, Weiland e May, mas atualmente elas são pouco usadas e divulgadas. As classificações mais empregadas na literatura médica são a de Lew e Waldvogel, ${ }^{3}$ e a de Cierny e Mader, ${ }^{4}$ e Cierny et al. ${ }^{5}$

Lew e Waldvogel ${ }^{3}$ classificam a osteomielite como tendo três etiologias possíveis: hematogênica, por contiguidade, e crônica.

Cierny e Mader ${ }^{4}$ e Cierny et $\mathrm{al}^{5}$ levam em consideração o padrão do acometimento ósseo de acordo com a etiologia (tipos 1 a 4) (-Fig. 1), e as condições do hospedeiro (tipos A, B
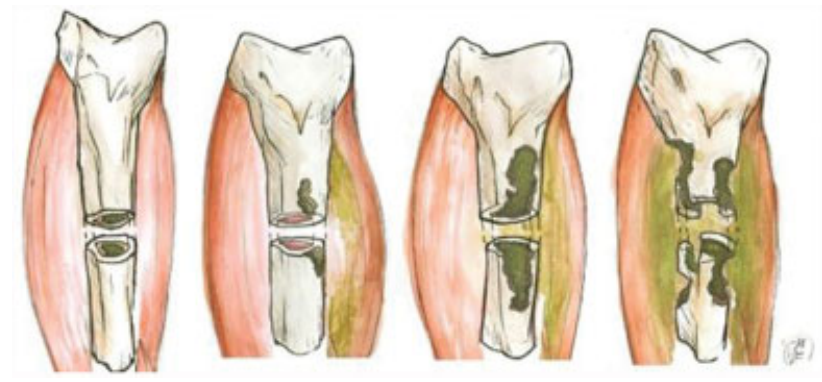

Fig. 1 Classificação de Ciernye Mader para osteomielite quanto ao padrão de acometimento ósseo. Tipo 1, medular; tipo 2, superficial; tipo 3, permeativa estável; tipo 4, permeativa instável. 
sistêmico, B local, B ambos, C). Essa classificação tem como objetivo orientar decisões no tratamento.

Tipo 1-intramedular, geralmente decorrente de pinagem intramedular.

Tipo 2-superficial, geralmente decorrente de contiguidade de úlcera de pressão.

Tipo 3-permeativa estável, em que a infecção penetra a camada cortical e adentra a medular, mas o osso permanece biomecanicamente estável (aguenta carga). É geralmente observada no pós-operatório infectado de osteossíntese com placa.

Tipo 4-permeativa instável, em que a infecção é extensa, acomete a camada cortical e medular, e o osso é biomecanicamente instável. Pode ocorrer após infecção agressiva ou após desbridamento extenso.

Hospedeiro A - paciente e membros sadios.

Hospedeiro B sistêmico - antecedente de diabetes mellitus, senilidade, uso de álcool ou drogas, imunodeficiências.

Hospedeiro B local - queimadura prévia no local, cicatriz, celulite, cirurgia prévia, e doença vascular local.

Hospedeiro B sistêmico e local - combina acometimentos sistêmicos e locais.

Hospedeiro C - múltiplas comorbidades que tornam o paciente incapaz de suportar o tratamento. ${ }^{4-6}$

\section{Patogenia e biofilme}

A compreensão patogênica também se modificou com o entendimento sobre o comportamento de bactérias na formação do biofilme. Esse conhecimento permitiu compreender fenômenos de recidiva de infecções, resistência aos antibióticos, e o impacto da presença de implante cirúrgico no sítio infectado. ${ }^{1,7}$

As bactérias formadoras de biofilme existem em duas formas: planctônica e fixa. Na forma planctônica (livre), as bactérias encontram-se livres fora da matriz extracelular, e estão isoladas e vulneráveis aos mecanismos de defesa do hospedeiro. Entretanto, quando há um volume elevado de bactérias planctônicas, é possível ocorrer a migração para a corrente sanguínea, o que resulta em septicemia. A bactéria planctônica pode se aderir a uma superfície como tecido necrosado ou corpo estranho (implante cirúrgico), e tornarse fixa. Já na forma fixa (séssil), as bactérias sésseis tendem a formar um biofilme de polissacarídeo sobre a superfície tecidual ou o implante.

Após a colonização e a formação do biofilme, as bactérias podem permanecer inertes ou se manifestar por meio de infecção. A infecção instaurada na presença de biofilme é mais resistente aos antibióticos. Isso ocorre pelo fato de o antibiótico presente não ultrapassar o glicocálix (camada mais externa) do biofilme de forma efetiva (com gradiente de concentração baixa na região em que as bactérias estão alojadas). No centro das colônias, as bactérias se encontram em estado de baixo metabolismo, e dificultam a ação de determinados antibióticos. Tal fato pode explicar a maior resistência aos antibióticos nas infecções crônicas (com mais bactérias latentes) do que nas infecções agudas ${ }^{7,8}$ (- Fig. 2).

A interação da colônia com o tecido hospedeiro e a ação imunológica podem levar à formação de osso necrosado encapsulado, que pode também ser colonizado, e dá origem ao sequestro ósseo. ${ }^{7}$ Essa coleção pode se estender para fora, com a formação de um trajeto sinusal até a pele, e dá origem a fístulas $^{9}$ (-Fig. 3).

\section{Fraturas e infecção}

A osteomielite relacionada às fraturas ocorre geralmente nos cenários de exposição óssea ou após tratamento cirúrgico (com ou sem colocação de implante). Nas fraturas expostas, a contaminação é certamente presente. Os determinantes

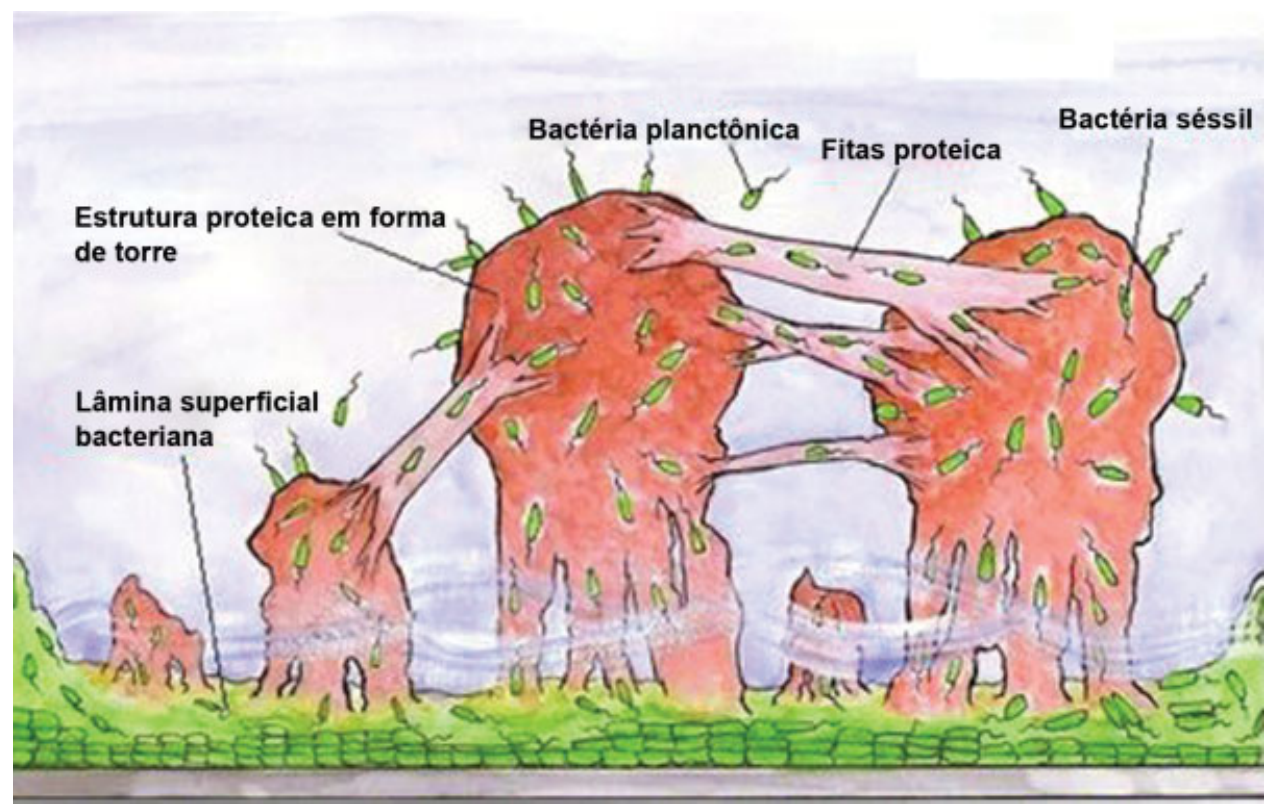

Fig. 2 Modelo estrutural do biofilme bacteriano. Notar a presença de lâmina superficial bacteriana aderida ao material metálico, a estrutura proteica de torres com bactérias em trânsito em seu interior, o fluido líquido na base das torres, e as fitas proteicas que permitem o trânsito bacteriano. Há a presença de bactérias planctônicas em volta do biofilme. 


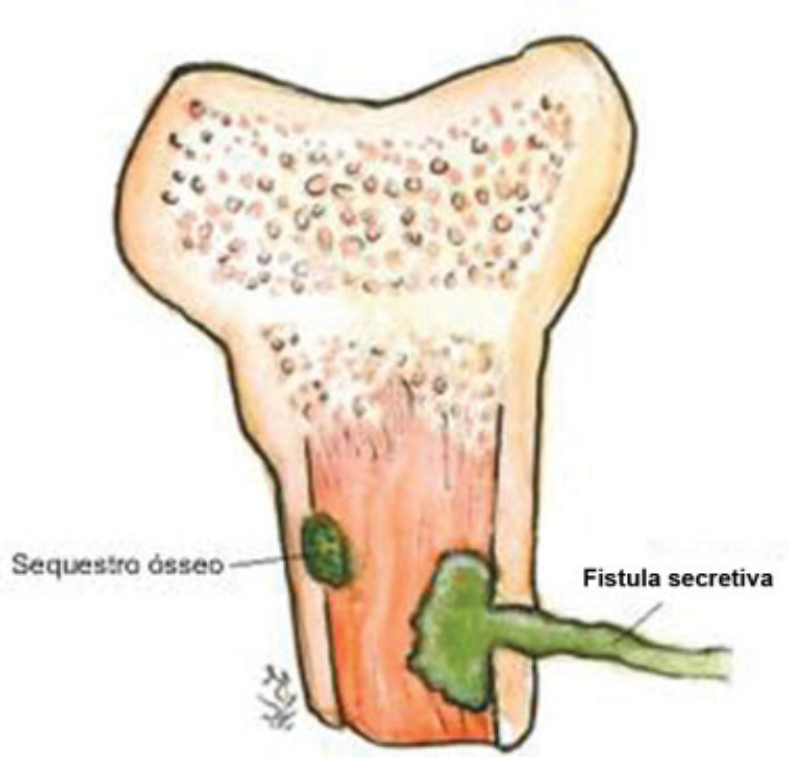

Fig. 3 Fenômenos de interação entre o tecido infeccioso e o hospedeiro levam à formação de sequestro ósseo e fístula.

associados à evolução da contaminação para infecção são a resposta imunológica do hospedeiro, a capacidade da limpeza mecânica de diminuir a concentração bacteriana no local, e o desbridamento para deixar tecido saudável e viável na ferida, menos suscetível à aderência bacteriana.

\section{Microbiologia}

Quanto ao patógeno, muitas vezes as bactérias identificadas agudamente na ferida exposta não são as que causarão a infecção crônica. Os patógenos hospitalares mais agressivos ganham importância nesse cenário de fratura exposta, pois podem contaminar e causar infecção nos dias seguintes ao acidente, mesmo após tratamento inicial adequado com limpeza e desbridamento. ${ }^{3}$

Na osteomielite crônica, geralmente decorrente de uma infecção aguda incorretamente tratada ou após procedimento cirúrgico, o patógeno pode ser pertencente à flora típica hospitalar (Pseudomonas aeruginosa, outros Gram-negativos, Staphilococcus aureus), ou pode ser polibacteriana. ${ }^{8}$

A osteomielite fúngica está mais relacionada aos pacientes imunocomprometidos, diabéticos ou invadidos por cateteres. A disseminação pode ser hematogênica ou por contiguidade, $\mathrm{e}$ o agente mais comum é a Candida $s p .^{1,3}$

\section{Avaliação e diagnóstico}

A avaliação do paciente começa com a coleta detalhada do histórico clínico. Informações como infecção prévia focal ou sistêmica podem levantar suspeita quanto à disseminação infecciosa para um determinado sítio, seja o evento recente ou remoto. Histórico de trauma prévio que levou a complicação local de pele ou de partes moles também é um dado relevante. A ocorrência de fratura e suas características, como grau de exposição e tratamento instituído (cirurgia para limpeza local, fixação de fraturas, desbridamentos, presença de implante ou corpo estranho), são fundamentais na abordagem inicial do paciente.
As manifestações específicas podem incluir dor local profunda (óssea), calor, edema e eritema cutâneo, além de sintomas gerais, como inapetência e febre. Ferida cirúrgica secretiva purulenta ou formação de fístulas cutâneas também são achados da inspeção bastante sugestivos. ${ }^{7}$

Exames laboratoriais relevantes incluem hemograma, pois a leucocitose é o principal marcador sugestivo nas infecções agudas. Já na osteomielite crônica, os valores celulares do leucograma podem ser normais. Os marcadores inflamatórios como a velocidade de hemossedimentação (VHS) e a proteína $C$ reativa (PCR) sérica se elevam na fase aguda de infecção e, após manipulação cirúrgica, a PCR tem pico no terceiro dia pós-manipulação, e a VHS, no quinto dia. A PCR retorna ao seu valor normal dentro de três semanas, enquanto a VHS leva um tempo maior. Um novo pico no valor da PCR três dias após a manipulação cirúrgica ou introdução da antibioticoterapia é sugestivo de reinfecção ou falha do tratamento. Valores normais de ambos os exames são excelentes preditivos de ausência de osteomielite. Têm valor no seguimento da osteomielite mediante a análise seriada, e o PCR é o primeiro marcador a decair diante de uma resposta satisfatória ao tratamento. ${ }^{7,10,11}$

A hemocultura não é muito útil, pois apresenta resultado negativo mesmo na vigência de osteomielite, principalmente quando não houver septicemia. ${ }^{1}$

A radiografia geralmente é normal na fase aguda, principalmente nas primeiras duas semanas, no caso da osteomielite hematogênica. A presença de fratura, calo ósseo ou implante cirúrgico pode mascarar achados específicos da infecção. Os achados relacionados na fase tardia da osteomielite crônica são, em alguns casos, rarefação óssea local atipicamente bem localizada ou lesões líticas (que surgem após a destruição de 50 a 75\% da matriz óssea). Outras anormalidades incluem formação de sequestro ósseo visível, esclerose óssea, neoformação e espessamento cortical, além de reação periosteal. ${ }^{10,12}$

A cintilografia óssea com eritrócitos marcados por tecnécio-99 ou índio, com leucócitos marcados por gálio-67, ou com os marcadores da atividade da medula óssea têm sido recurso útil no rastreio e no diagnóstico precoce da osteomielite. A cintilografia óssea realça áreas de atividade inflamatória, mas existe divergência sobre qual marcador seria mais sensível (em termos de rastreio e maior sensibilidade) para a detecção precoce da osteomielite. ${ }^{10,13,14}$

Já a cintilografia com gálio-67 realça áreas de concentração leucocitária, geralmente sítios de infecção, mas também tumores. O exame com gálio-67 é o mais indicado para avaliar complicações de osteomielite, exceto na coluna vertebral. ${ }^{13,15}$ A atividade da medula óssea pode ser avaliada indiretamente mediante a marcação local por coloides de tecnécio-99m em exame trifásico.

Outros marcadores têm sido propostos como forma de oferecer exame mais específico para diagnóstico e seguimento da osteomielite crônica, entre eles a inbiotina para infecções vertebrais. Fragmentos radiomarcados de ubiquicidina prometem realçar tecidos bacterianos. ${ }^{14}$

A tomografia computadorizada pode auxiliar no estabelecimento da extensão dos fragmentos ósseos para partes moles, na melhor caracterização do sequestro ósseo, e, além 
de oferecer imagens detalhadas da camada cortical óssea, permite avaliar a estabilidade axial.

A ressonância magnética permite estudo detalhado da extensão da infecção, inclusive para partes moles. Geralmente as áreas acometidas são realçadas com hipersinal em T2, como: coleção secretiva muscular ou no tecido subcutâneo e edema ósseo, que caracterizam aumento da atividade inflamatória nesse local. As alterações agudas podem ser detectadas mais precocemente por meio desse exame, em situações em que as radiografias simples do segmento são normais. Na cronificação da infecção, reações periosteais podem ser verificadas de forma mais precisa, com a visualização de adensamento lamelar (formação da reação em "casca de cebola"), ou a interrupção desse processo, que leva à formação do "triângulo de Codman". ${ }^{10} \mathrm{O}$ exame pode sofrer interferência da manipulação cirúrgica e apresentar artefatos devido à presença de implantes metálicos. ${ }^{1,10}$

A tomografia com emissão de pósitrons (TEP) com o marcador 2-[18F]-fluoro-2-desoxi-D-glucose (FDG) é outro recurso de imagem promissor, com sensibilidade elevada de aproximadamente $95 \%$ e especificidade também elevada, que varia entre $75 \%$ e $99 \%$. Esse método apresenta como limitação em muitos cenários clínicos a pouca disponibilidade e o custo elevado. ${ }^{15}$

As culturas de secreção de ferida, de fratura exposta e de fístula não apresentam concordância com patógeno causador da osteomielite em muitos casos. A literatura é dividida quanto a este ser um método diagnóstico relevante. 0 tratamento baseado na bactéria "errada" (identificada por meio de cultura) pode prejudicar o paciente, e resultar em uso ineficaz de antibiótico, o que estimula o desenvolvimento de resistência. ${ }^{9,10}$

A biópsia óssea da região acometida é um método preferencial, principalmente na osteomielite crônica, em que o isolamento sanguíneo do patógeno é muito pouco provável. ${ }^{10}$ Outro recurso diagnóstico é a sonicação de implantes cirúrgicos (inclusive próteses) removidos de sítios infectados. O material é submetido a preparação e aplicação de ondas ultrassônicas que quebram estruturalmente o biofilme bacteriano, e permitem a identificação molecular do agente etiológico da infecção. ${ }^{16,17}$ Outras técnicas de microbiologia, como a cadeia de reação de polimerase, são também usadas, mas restritas principalmente aos cenários acadêmico e de pesquisa. ${ }^{10}$

\section{Tratamento}

O tratamento da osteomielite crônica deve ser multifásico e envolver basicamente três estratégias combinadas: 1 ) compensação clínica do paciente; 2 ) tratamento medicamentoso com antibioticoterapia; e 3) abordagem cirúrgica.

\section{Compensação do paciente}

O primeiro passo após o diagnóstico é a melhora das condições clínicas do hospedeiro, com vistas ao controle de doenças sistêmicas como diabetes, desnutrição, imunossupressão, doença vascular, entre outras.

\section{Tratamento medicamentoso}

O antibiótico a ser usado deve, preferencialmente, ser de baixo custo, conveniente quanto à forma de administração e posologia, além de oferecer alta concentração sérica e no tecido ósseo. ${ }^{2,8}$

O uso dos antibióticos pode ser feito de três formas: sistêmica, seja como profilaxia ou tratamento; na solução de irrigação, a ser usada em limpeza cirúrgica; e em dispositivo a ser introduzido no paciente durante o procedimento cirúrgico.

\section{Antibióticos sistêmicos}

$\mathrm{O}$ uso no tratamento de fraturas expostas é baseado em recomendações empíricas, e carece de estudos que sustentem classe específica de medicação e tempo de uso. A literatura sustenta o uso de cefalosporina para fraturas de baixo grau de contaminação e associação de aminoglicosídeo para as mais contaminadas, com lesão de partes moles e com maior energia de trauma. A duração é controversa, os antibióticos normalmente são indicados por um período de um a três dias, e o uso estendido é reservado apenas aos casos em que haja sinais de infecção observados por meio da inspeção da ferida. ${ }^{10}$

O uso de antibiótico sistêmico para tratamento de infecção crônica não tem consenso na literatura quanto ao tempo de tratamento e à escolha da medicação, verificada mediante revisão sistemática. ${ }^{18}$ Há recomendações de esquemas de duas a seis semanas, para permitir melhora da ferida local e revascularização. No entanto, outros autores orientam que o tempo seja estendido por vários meses. ${ }^{1,8}$

Há muitas opções de drogas, mas existem recomendações baseadas em observações clínicas, estudos de eficácia, experiência clínica acumulada, e análise de resultados. Algumas opções já são consagradas entre especialistas, e são norteadas por protocolos difundidos no meio científico, como os trabalhos de Lima e Zumiotti ${ }^{2}$ no Brasil, e o protocolo da Korean Society for Chemotherapy ${ }^{19}$ de antibioticoterapia para infecções ósseas e articulares, de 2014 (- Tabela 1).

Nos casos de infecção crônica em que não há sepse, comprometimento sistêmico ou do membro, é possível interromper o uso de antibiótico uma semana antes da limpeza cirúrgica e da coleta de material para cultura. A medicação empírica é iniciada imediatamente após a cirurgia, e é substituída pela terapia específica após os resultados dos exames de cultura e antibiograma.

Em pacientes sépticos, a antibioticoterapia deve ser iniciada durante a indução anestésica do procedimento cirúrgico a ser feito (limpeza cirúrgica, que será discutida a seguir neste trabalho), com o objetivo de diminuir o risco de bacteremia e suas complicações, sem comprometer o resultado de cultura bacteriana a partir de material coletado. ${ }^{2,8}$

Antibióticos por aplicação direta na ferida operatória O uso de antibióticos diluídos nas soluções de irrigação mostrou resultados controversos e representou aumento de custo considerável ao tratamento, não sendo rotineiramente recomendado. ${ }^{1,10}$

Os antibióticos podem ser carregados por meio de dispositivos confeccionados com cimento cirúrgico de polimetilmetacrilato (PMMA). Deve-se atentar que muitos antibióticos não são termorresistentes e não são passíveis de ser usados dessa 
632 Osteomielite crônica pós-operatória nos ossos longos Heitzmann et al.

Tabela 1 Principais agentes etiológicos bacterianos presentes na osteomielite e respectivos antibióticos para o tratamento

\begin{tabular}{|c|c|c|}
\hline Organismo & Primeira opção de antibióticos & Antibióticos opcionais \\
\hline $\begin{array}{l}\text { Staphylococcus aureus ou } \\
\text { estafilococos coagulase } \\
\text { negativos sensíveis } \\
\text { à meticilina }\end{array}$ & Oxacilina ou cefazolina. & $\begin{array}{l}\text { Vancomicina ou clindamicina ou } \\
\text { ampicilina/sulbactam. }\end{array}$ \\
\hline $\begin{array}{l}\text { S. aureus resistente à } \\
\text { meticilina (SARM) ou }\end{array}$ & $\begin{array}{l}\text { Vancomicina (associada ou não a } \\
\text { rifampcina) ou teicoplanina. }\end{array}$ & Linezolida ou sulfametoxazol/trimetoprim \\
\hline $\begin{array}{l}\text { estafilococos coagulase } \\
\text { negativos } \\
\text { resistentes à meticilina }\end{array}$ & & $\begin{array}{l}\text { (associados ou não a rifampcina), ou daptomicina } \\
\text { (associada ou não a rifampcina), ou tigeciclina, } \\
\text { ou clindamicina, ou fluoroquinolona } \\
\text { (associadas ou não a rifampcina). }\end{array}$ \\
\hline Streptococcus spp. & $\begin{array}{l}\text { Penicilina ou ceftriaxona, ou } \\
\text { cefazolina, ou vancomicina. }\end{array}$ & Clindamicina ou vancomicina, ou fluoroquinolona. \\
\hline Enterococcus spp. & $\begin{array}{l}\text { Penicilina ou ampicilina + gentamicina } \\
\text { (associação). }\end{array}$ & $\begin{array}{l}\text { Ampicilina/sulbactam ou linezolida, ou daptomicina, } \\
\text { ou tigeciclina associada a rifampcina. }\end{array}$ \\
\hline Pseudomonas spp. & Cefepime ou meropenem ou imipenem. & Fluoroquinolona. \\
\hline $\begin{array}{l}\text { Enterobactérias } \\
\text { produtoras de BLEA }\end{array}$ & Ertapenem ou imipenem, ou meropenem. & Ceftriaxona. \\
\hline $\begin{array}{l}\text { Enterobactérias não } \\
\text { produtoras de BLEA }\end{array}$ & Ceftriaxona ou fluoroquinolona. & Ceftriaxona. \\
\hline \multirow[t]{3}{*}{ Anaeróbios } & Amoxicilina/Clavulanato ou & Metronidazol ou clindamicina, \\
\hline & ampicilina/sulbactam, ou & ou meropenem, ou imipenem. \\
\hline & piperacilina/tazobactam. & \\
\hline $\begin{array}{l}\text { Polimicrobiana aeróbia } \\
\text { e anaeróbia }\end{array}$ & Amoxicilina/Clavulanato. & Ertapenem. \\
\hline
\end{tabular}

Abreviaturas: BLEA, beta-lactamases de espectro ampliado.

Notas: Adaptado a partir de Lima e Zumiotti ${ }^{2}$ e do protocolo da Korean Society for Chemotherapy ${ }^{19}$ de antibioticoterapia para infecções ósseas e articulares.

forma, pois perdem sua ação. Esses dispositivos podem ser no formato de pérolas ou de hastes cimentadas, por exemplo. Uma vez que o antibiótico seja absorvido e tenha atuado no sítio infeccioso, o dispositivo residual de PMMA deve ser retirado em novo procedimento cirúrgico, pois pode servir de hospedeiro para contaminação secundária, e atuar como novo foco de manutenção da infecção. ${ }^{15,20}$

Os dispositivos de sulfato de cálcio também são opção de veículo para o antibiótico, embora existam resultados divergentes quanto aos resultados de seu uso. ${ }^{21}$

Outra opção que não as pérolas ou dispositivos de PMMAé o osso artificial biodegradável com antibiótico. Há relato de pesquisadores de Toronto, Canadá, de equivalência quanto à eficácia em comparação com o PMMA. O osso artificial biodegradável com antibiótico apresenta segurança e não exige reabordagem para retirada do material. ${ }^{22}$

Entre as medicações que podem ser combinadas ao cimento estão os aminoglicosídeos e vancomicina, e esta última é a mais útil no manejo de infecções operatórias causadas por bactérias Gram-positivas resistentes. ${ }^{8}$

Com relação à concentração de antibiótico liberada pelo dispositivo para o tecido, os veículos com maior superfície de contato (como as pequenas pérolas de cimento) permitem melhor distribuição local da medicação. 0 pico de concentração costuma ser atingido entre as primeiras $24 \mathrm{~h}$ e $48 \mathrm{~h}$; depois, ocorre queda constante. A maioria dos antibióticos mantém-se com concentração mínima efetiva local por pelo menos 30 dias. $^{23}$

Os dispositivos não absorvíveis costumam ser retirados mediante novo procedimento cirúrgico após quatro a oito semanas de sua instalação ${ }^{23,24}$ (- Tabela 2).

\section{Terapias complementares}

A oxigenoterapia hiperbárica tem sido usada por mais de 60 anos em todo o mundo. ${ }^{25} \mathrm{O}$ tratamento envolve a respiração de oxigênio na concentração de $100 \%$ sob condições hiperbáricas, e promove entrada sob pressão de oxigênio na circulação sanguínea do indivíduo e chegada aos tecidos. A hiperoxigenação tissular provoca efeitos terapêuticos específicos, inclusive estimulação da lise bacteriana por leucócitos, aumento da proliferação de fibroblastos e colágeno na ferida, neovascularização de tecidos isquêmicos ou irradiados, imunomodulação, como a redução de mediadores pró-inflamatórios, e a redução dos efeitos da isquemia-reperfusão nos tecidos isquêmicos. ${ }^{26}$ Como consequência, a terapia hiperbárica promove tanto efeitos diretos para controle da infecção quanto melhora indireta das condições tissulares da ferida, e promove o aprimoramento na cicatrização. ${ }^{25}$

\section{Tratamento cirúrgico}

As abordagens cirúrgicas na osteomielite crônica têm por objetivo a remoção mecânica dos tecidos infectados e 
Tabela 2 Principais antibióticos usados com dispositivos internos (cimento cirúrgico e outros) para o tratamento da osteomielite, seus respectivos picos de concentração local na ferida, e duração da dose eficaz disponível ${ }^{23}$

\begin{tabular}{|l|l|l|l|}
\hline Antibiótico & Veículo & Pico de concentração & Duração \\
\hline Gentamicina 10\% & Polimetilmetacrilato & 3 dias & $>30$ dias com dose eficaz \\
\hline Vancomicina 10\% & Polimetilmetacrilato & 1 dia & $>30$ dias com dose eficaz \\
\hline Cefepima 10\% & Polimetilmetacrilato & 2 dias & 8 a 9 dias com dose eficaz \\
\hline Tobramicina 10\% & 1-tricálcio fosfato-silicato-xerogel & 1 dia & 9 dias com dose eficaz \\
\hline $\begin{array}{l}\text { Ertapenem/ } \\
\text { Meropenem 10\% }\end{array}$ & Polimetilmetacrilato & 1-2 dias & $\begin{array}{l}>30 \text { dias, mas, a partir do quarto dia, } \\
\text { com dose abaixo do eficaz }\end{array}$ \\
\hline
\end{tabular}

desvitalizados. Em algumas situações, o paciente não apresenta condições clínicas que permitam prosseguir com o tratamento cirúrgico (hospedeiro tipo $C$ na classificação de Cierny e Mader)., 3,10 É importante ressaltar que a manutenção da estabilidade axial óssea, sempre que possível, deve ser preservada.

\section{Cierny e Mader tipo 1 (osteomielite crônica medular)} A fresagem intramedular seguida de lavagem do canal é uma técnica preconizada para o tratamento (reamer-irrigator-aspirator, RIA). O uso de haste intramedular de cimento impregnada com antibióticos tem sido promissor, assim como a associação com a fresagem prévia. ${ }^{27}$ Bharti et $\mathrm{al}^{20}$ propuseram recentemente uma forma de confecção de haste de PMMA que permite maior facilidade na introdução por meio do canal medular, mesmo os mais estreitos.

O procedimento de Lautenbach envolve a combinação de desbridamento acompanhado de fresagem intramedular e introdução de um tubo/sonda de duplo lúmen, que permite a introdução de antibiótico no local abordado, coleta de material para análise laboratorial, e cultura. ${ }^{28}$

\section{Cierny e Mader tipo 2 (osteomielite superficial)}

O tratamento principal consiste na remoção mecânica dos tecidos acompanhada de limpeza exaustiva com soro fisiológico, e ele dilui as populações bacterianas na forma planctônica no local abordado, e prejudica o novo processo de adesão bacteriana à superfície. Substâncias tipo sabão são promissoras quanto ao aprimoramento da limpeza, além de ser inócuas. ${ }^{10} \mathrm{~A}$ irrigação pulsátil, de maneira prática, apresenta melhor potencial de remoção mecânica das bactérias aderidas no sítio de infecção. A irrigação sob alta pressão pode lesionar os tecidos locais, levar as bactérias para locais mais profundos, e é prejudicial. ${ }^{1} \mathrm{~A}$ irrigação sob baixa pressão poderia oferecer os benefícios da limpeza sem lesionar o local, mas existem divergências quanto à maior eficácia em comparação com a limpeza com jato gravitacional convencional. Alguns trabalhos sustentam menor capacidade de limpeza em comparação com o uso de dispositivo de alta pressão. ${ }^{29,30}$ O uso de substâncias oxidantes também é controverso, pois também leva à lesão tecidual local. ${ }^{1}$ A cobertura de partes moles deve ser priorizada, e geralmente não há dificuldade em obtê-la.

\section{Cierny e Mader tipo 3 (permeativo estável)}

O tratamento cirúrgico visa à ressecção ampla de qualquer tecido ósseo ou de partes moles atingidos pela infecção ou desvitalização. A abordagem multidisciplinar cirúrgica agressiva envolve desbridamento extenso e enxertia para cobertura de perda óssea, e a feitura de retalhos cutâneos para a cobertura de partes moles tem mostrado bons resultados em alguns cenários como infecções permeativas restritas ou extensas. Fixação interna ou externa pode ser necessária (depende do volume tecidual ressecado), a fim de manter a estabilidade axial do segmento/membro. Apesar da agressividade da abordagem e da exigência de recursos para o tratamento multidisciplinar nesses moldes, pesquisadores de Sydney ${ }^{31}$ e Istambul ${ }^{32}$ mostraram resultados bons quanto à erradicação da infecção e o retorno dos pacientes ao trabalho e às atividades diárias.

Outra opção recentemente proposta nos últimos anos para casos que necessitam de ressecção ou desbridamento amplo é o uso de espaçador de PMMA para preencher o espaço morto. A técnica da membrana induzida ou Masquelet é um procedimento cirúrgico de duas etapas usado para tratar pseudoartrose, defeitos ósseos e osteomielite. O organismo hospedeiro forma uma membrana em volta do espaçador por meio do fenômeno de membrana, em que ocorre aumento da vascularização e produção de fatores de crescimento (fator de crescimento vascular endotelial [FCVE], fator de transformação do crescimento beta 1 [FTC beta 1] e proteína óssea morfogenética 2 [POM 2]). 0 espaçador então é retirado em uma segunda abordagem após seis a oito semanas, e é introduzido enxerto ósseo esponjoso para preencher o espaço delimitado pela nova membrana biológica. A estabilização pode ser obtida com fixação interna com o uso de placas e parafusos, assim como com a fixação externa. A cobertura de partes moles pode ser obtida com feitura de retalho miocutâneo, se necessário. ${ }^{33-36}$

Muitos autores introduziram variantes na técnica que incluíram o uso de espaçadores revestidos com antibiótico, fixação interna durante a primeira etapa, uso da técnica RIA, enxerto da crista ilíaca, substitutos ósseos, e fatores de crescimento. ${ }^{32,33}$ Entretanto, pacientes submetidos a essa técnica por infecções ósseas apresentaram maior risco de complicações cirúrgicas em outras observações clínicas. ${ }^{33}$

A técnica de Papineau, ${ }^{37}$ descrita originalmente em 1973, voltou a fazer parte do arsenal terapêutico do tratamento da osteomielite crônica a partir de 2006 com a associação da 
aplicação de curativo a vácuo à técnica original. Tal associação permite aumento do fluxo sanguíneo local, remoção do líquido intersticial, e consequente diminuição na contagem de bactérias no leito formado após a ressecção de tecido osteomielítico. $^{38}$

O biovidro é um material disponibilizado recentemente, que tem sido usado no tratamento cirúrgico da osteomielite com as finalidades de manejo de espaço morto ósseo após curetagem ou ressecção. Defende-se que a alteração do $\mathrm{pH}$ tecidual promovido pelo biovidro resulte em ambiente tecidual mais favorável ao controle da infecção crônica. ${ }^{39}$

Cierny e Mader tipo 4 (permeativa extensa e instável) O tratamento cirúrgico com ressecção pode resultar na perda elevada de volume tecidual, e exige o uso de técnicas de microcirurgia e reconstrução óssea tanto para garantir a estabilidade axial óssea quanto a cobertura de partes moles e o fechamento de ferida. ${ }^{40} \mathrm{Em}$ casos extremos, a amputação do membro pode ser necessária para a preservação da vida. ${ }^{1}$

Uma opção possível é a instalação de fixador externo circular após a ressecção, pois permite o alongamento ósseo. 0 transporte ósseo por osteogênese sob distração é o método de escolha nos defeitos ósseos residuais maiores do que $4 \mathrm{~cm}$ de comprimento. As técnicas reconstrutivas e de flap muscular permitem obtenção de melhor cobertura óssea, e podem ser usadas junto com o fixador externo. ${ }^{41,42}$

Uma modernização do transporte ósseo é sua associação com a técnica de Masquelet, e agrega as vantagens de preenchimento de espaço morto, formação de pertuito para ocorrer o transporte, além de prevenir a absorção do enxerto e estimular a consolidação do defeito. ${ }^{36}$

O uso de enxerto de fíbula vascularizada também é relatado na literatura como uma opção para manejar defeitos ósseos tibiais de 5 a $6 \mathrm{~cm}$ de comprimento, em um ambiente de vascularização local ruim, como nas infecções extensas. ${ }^{43,44}$

\section{Considerações finais}

O tema osteomielite tem apresentado novas atualizações na literatura médica e acúmulo de conhecimento, principalmente quanto ao melhor entendimento dos fenômenos patogênicos e de desenvolvimento das infecções crônicas pós-operatórias, assim como novas técnicas e opções de tratamento cirúrgico.

A definição, as classificações históricas e as mais usadas recentemente estão bem estabelecidas e foram apresentadas neste trabalho, assim como as teorias patogênicas.

O diagnóstico sugestivo clínico já é bem documentado. No entanto, existem novidades quanto ao uso de exames laboratoriais, de imagem e de microbiologia para confirmação diagnóstica, seguimento da doença e coleta de informações importantes para guiar o tratamento. 0 tratamento da osteomielite crônica de ossos longos apresenta divergências quanto ao manejo clínico e medicamentoso, principalmente por muitas recomendações ainda não serem baseadas em evidência científica sólida. No entanto, protocolos e trabalhos isolados mostram combinações de tratamento bemsucedidas. O tratamento cirúrgico tem evoluído de forma importante nos últimos anos, com a introdução de novas técnicas para limpeza do tecido infeccioso, uso de substitutos ósseos para manejo de espaço morto e manutenção de estabilidade, novos implantes de fixação, e uso local de antibióticos associados.

O conhecimento reunido permite estabelecer estratégias de tratamento combinado (clínico e cirúrgico) promissoras, e que mostram resultados satisfatórios em diversos cenários e situações. Como consequência, o domínio desse tema por ortopedistas e infectologistas permite o melhor manejo dos pacientes acometidos pela osteomielite crônica de ossos longos.

Este trabalho permitiu reunir as informações clássicas e as inovações relacionadas à doença osteomielite crônica e a seu tratamento, e oferecer material de atualização para auxiliar os profissionais envolvidos com o tratamento da osteomielite crônica na tomada de decisão terapêutica.

\section{Conflitos de Interesse}

Os autores declaram não haver conflitos de interesse.

\section{Referências}

1 Mast NH, Horwitz D. Osteomyelitis: a review of current literature and concepts. Oper Tech Orthop 2002;12(04):232-241

2 Lima ALLM, Zumiotti AV. Aspectos atuais do diagnóstico e tratamento das osteomielites. Acta Ortop Bras 1999;7(03):135-142

3 Lew DP, Waldvogel FA. Osteomyelitis. Lancet 2004;364 (9431):369-379

4 Cierny G, Mader JT. Adult chronic osteomyelitis. A review. In: D'Ambrosia RD, Marier RL, editors. Orthopaedic infections. Thorofare, NJ: Slack; 1989:31-48

5 Cierny G III, Mader JT, Penninck JJ. A clinical staging system for adult osteomyelitis. Clin Orthop Relat Res 2003; ((414):7-24

6 Mader JT, Shirtliff M, Calhoun JH. Staging and staging application in osteomyelitis. Clin Infect Dis 1997;25(06):1303-1309

7 Hake ME, Oh JK, Kim JW, et al. Difficulties and challenges to diagnose and treat post-traumatic long bone osteomyelitis. Eur J Orthop Surg Traumatol 2015;25(01):1-3

8 Jorge LS, Chueire AG, Rossit ARB. Osteomyelitis: a current challenge. Braz J Infect Dis 2010;14(03):310-315

9 Mackowiak PA, Jones SR, Smith JW. Diagnostic value of sinus-tract cultures in chronic osteomyelitis. JAMA 1978;239(26):2772-2775

10 Lazzarini L, Mader JT, Calhoun JH. Osteomyelitis in long bones. J Bone Joint Surg Am 2004;86(10):2305-2318

11 Alrashidi Y, Galhoum AE, Wiewiorski M, et al. How to diagnose and treat infection in totalankle arthroplasty. Foot Ankle Clin 2017;22(02):405-423

12 Butt WP. The radiology of infection. Clin Orthop Relat Res 1973;96 (96):20-30

13 Sapienza MT, Hironaka F, Lima ALLM, et al. Avaliação de atividade inflamatória na osteomielite crônica. Contribuição da cintilografia com anticorpos policlonais. Rev Assoc Med Bras (1992) 2000; 46(02):106-112

14 Love C, Palestro CJ. Nuclear medicine imaging of bone infections. Clin Radiol 2016;71(07):632-646

15 Hogan A, Heppert VG, Suda AJ. Osteomyelitis. Arch Orthop Trauma Surg 2013;133(09):1183-1196

16 Trampuz A, Piper KE, Jacobson MJ, et al. Sonication of removed hip and knee prostheses for diagnosis of infection. N Engl J Med 2007; 357(07):654-663

17 Piper KE, Jacobson MJ, Cofield RH, et al. Microbiologic diagnosis of prosthetic shoulder infection by use of implant sonication. J Clin Microbiol 2009;47(06):1878-1884 
18 Conterno LO, Turchi MD. Antibiotics for treating chronic osteomyelitis in adults. Cochrane Database Syst Rev 2013;(09): CD004439

19 Korean Society for Chemotherapy. Korean Society ofInfectious Diseases; Korean Orthopaedic Association. Clinicalguidelines for the antimicrobial treatment of bone and jointinfections in Korea. Infect Chemother 2014;46(02):125-138

20 Bharti A, Saroj UK, Kumar V, Kumar S, Omar BJ. A simple method for fashioning an antibiotic impregnated cemented rod for intramedullary placement in infected non-union of long bones. J Clin Orthop Trauma 2016;7(Suppl 2):171-176

21 Luo S, Jiang T, Yang Y, Yang X, Zhao J. Combination therapy with vancomycin-loaded calcium sulfate and vancomycin-loaded PMMA in the treatment of chronic osteomyelitis. BMC Musculoskelet Disord 2016;17(01):502

22 McKee MD, Li-Bland EA, Wild LM, Schemitsch EH. A prospective, randomized clinical trial comparing an antibiotic-impregnated bioabsorbable bone substitute with standard antibiotic-impregnated cement beads in the treatment of chronic osteomyelitis and infected nonunion. J Orthop Trauma 2010;24(08):483-490

23 Nandi SK, Bandyopadhyay S, Das P, et al. Understanding osteomyelitis and its treatment through local drug delivery system. Biotechnol Adv 2016;34(08):1305-1317

24 Gálvez-López R, Peña-Monje A, Antelo-Lorenzo R, et al. Elution kinetics, antimicrobial activity, and mechanical properties of 11 different antibiotic loaded acrylic bone cement. Diagn Microbiol Infect Dis 2014;78(01):70-74

25 Calzia E, Oter S, Muth CM, Radermacher P. Evolving career of hyperbaric oxygen in sepsis: From augmentation of oxygen delivery to the modulation of the immune response. Crit Care Med 2006;34(10):2693-2695

26 Marx RE, Ehler WJ, Tayapongsak P, Pierce LW. Relationship of oxygen dose to angiogenesis induction in irradiated tissue. Am J Surg 1990;160(05):519-524

27 Kanakaris N, Gudipati S, Tosounidis T, Harwood P, Britten S, Giannoudis PV. The treatment of intramedullary osteomyelitis of the femur and tibia using the Reamer-Irrigator-Aspirator system and antibiotic cement rods. Bone Joint J 2014;96-B(06): 783-788

28 Hashmi MA, Norman P, Saleh M. The management of chronic osteomyelitis using the Lautenbach method. J Bone Joint Surg Br 2004;86(02):269-275

29 Fry DE. Pressure Irrigation of Surgical Incisions and Traumatic Wounds. Surg Infect (Larchmt) 2017;18(04):424-430

30 Bhandari M, Thompson K, Adili A, Shaughnessy SG. High and low pressure irrigation in contaminated wounds with exposed bone. Int J Surg Investig 2000;2(03):179-182
31 Campbell R, Berry MG, Deva A, Harris IA, Harris IA. Aggressive management of tibial osteomyelitis shows good functional outcomes. Eplasty 2011;11:e3

32 Gülabi D, Erdem M, Ceçen GS. Treatment of chronic osteomyelitis of the femur with combined technique. Eklem Hastalik Cerrahisi 2014;25(03):173-178

33 Giannoudis PV, Harwood PJ, Tosounidis T, Kanakaris NK. Restoration of long bone defects treated with the induced membrane technique: protocol and outcomes. Injury 2016;47(47, Suppl 6): S53-S61

34 Wang X, Wang Z, Fu J, Huang K, Xie Z. Induced membrane technique for the treatment of chronic hematogenous tibia osteomyelitis. BMC Musculoskelet Disord 2017;18(01):33

35 Masquelet AC, Fitoussi F, Begue T, Muller GP. [Reconstruction of the long bones by the induced membrane and spongy autograft]. Ann Chir Plast Esthet 2000;45(03):346-353

36 Marais LC, Ferreira N. Bone transport through an induced membrane in the management of tibial bone defects resulting from chronic osteomyelitis. Strateg Trauma Limb Reconstr 2015;10 (01):27-33

37 Papineau LJ. L'excision-greffe avec fermeture retardée délibérée dans l'ostéomyélite chronique. Nouv Presse Med 1973;2(41): 2753-2755

38 Archdeacon MT, Messerschmitt P. Modern papineau technique with vacuum-assisted closure. J Orthop Trauma 2006;20(02): 134-137

39 Drago L, Romanò D, De Vecchi E, et al. Bioactive glass BAG-S53P4 for the adjunctive treatment of chronic osteomyelitis of the long bones: an in vitro and prospective clinical study. BMC Infect Dis 2013;13:584

$40 \mathrm{Wu} \mathrm{H}$, Shen J, Yu X, et al. Two stage management of Cierny-Mader type IV chronic osteomyelitis of the long bones. Injury 2017;48 (02):511-518

41 Kojima T, Kohno T, Ito T. Muscle flap with simultaneous mesh skin graft for skin defects of the lower leg. J Trauma 1979;19(10): 724-729

42 Lowenberg DW, Buntic RF, Buncke GM, Parrett BM. Long-term results and costs of muscle flap coverage with Ilizarov bone transport in lower limb salvage. J Orthop Trauma 2013;27(10): 576-581

43 Malizos KN, Zalavras CG, Soucacos PN, Beris AE, Urbaniak JR. Free vascularized fibular grafts for reconstruction of skeletal defects. J Am Acad Orthop Surg 2004;12(05):360-369

44 Zalavras CG, Femino D, Triche R, Zionts L, Stevanovic M. Reconstruction of large skeletal defects due to osteomyelitis with the vascularized fibular graft in children. J Bone Joint Surg Am 2007; 89(10):2233-2240 